\title{
Surgical Management of Primary Inferior Oblique Muscle Overaction: A Subgroup-Specific Surgical Approach
}

\author{
Ercan Ozsoy, ${ }^{1}$ (D) Abuzer Gunduz, 2 ㄴ) Emrah Ozturk, ${ }^{3}$ (1) Cem Cankaya ${ }^{2}$ \\ ${ }^{1}$ Department of Ophthalmology, Haseki Training and Research Hospital,University of Health Sciences, Istanbul, Turkey \\ ${ }^{2}$ Department of Ophthalmology, Inonu University Faculty of Medicine, Malatya, Turkey \\ ${ }^{3}$ Department of Ophthalmology, Malatya Training and Research Hospital, Malatya, Turkey
}

\begin{abstract}
Objectives: The aim of this research was to assess the surgical results of recession and myectomy procedures in a subgroup of patients who had primary inferior oblique muscle overaction.

Methods: The records of 94 patients who had been treated due to primary inferior oblique muscle overaction were retrospectively analyzed. The patients were classified into 2 groups according to the severity of the inferior oblique hyperfunction. Recession was performed for patients with a low grade $(+I$ or +2$)$ inferior oblique hyperfunction, and patients with high grade $(+3$ or +4$)$ hyperfunction underwent myectomy surgery. Patients demonstrating a horizontal misalignment underwent conventional horizontal muscle surgery along with an inferior oblique weakening procedure.

Results: A total of 134 eyes fulfilled the inclusion criteria. Recession was performed in 95 eyes and myectomy in 39. Surgical success was obtained in $96.8 \%$ of the eyes that underwent recession and $97.4 \%$ of the eyes that underwent myectomy. Residual inferior oblique hyperfunction was observed in 3 eyes after recession and in I eye after myectomy. After surgery, about one-quarter of the patients with unilateral inferior oblique overaction subsequently developed a contralateral inferior oblique overaction.

Conclusion: The results of this study demonstrated that both recession and myectomy procedures are effective for treating primary inferior oblique hyperfunction with minimal complications when applied in the appropriate patient.

Keywords: Myectomy, overactive, primary, recession.
\end{abstract}

\section{Introduction}

Inferior oblique muscle overaction (IOOA) is a common ocular motility disorder characterized by elevation of the affected eye during adduction and is often seen in conjunction with horizontal strabismus $(I, 2)$. IOOA is divided into primary and secondary types according to cause (3). The primary type, often bilateral with unknown etiology, has been reported in $72 \%$ of congenital esotropic cases, $34 \%$ of accommodative esotropic cases, and $32 \%$ of intermittent ex- otropic cases $(2,4)$. Secondary IOOA is unilateral and usually arises from palsy of the superior oblique muscle $(I, 2)$.

The primary type of IOAA results in overelevation of the adducted eye, smaller vertical strabismus in the primary gaze, a slight head tilt, and a negative head-tilt test. The secondary type results in paralyzed eye elevation upon adduction, hypertropia in the affected eye, a markedly abnormal head posture, and a positive Bielschowsky test $(I, 5)$.

In the treatment of IOOA, surgery is usually performed to correct misalignment and/or eliminate symptoms. Several

Address for correspondence: Ercan Ozsoy, MD. Saglik Bilimleri Universitesi, Haseki Egitim ve Arastirma Hastanesi, Goz Hastaliklari Anabilim Dali, Istanbul, Turkey

Phone: +90 5356983679 E-mail: ercanozy@hotmail.com

Submitted Date: October 18, 2019 Accepted Date: January 04, 2020 Available Online Date: February 17, 2020

${ }^{\circ}$ Copyright 2020 by Beyoglu Eye Training and Research Hospital - Available online at www.beyoglueye.com OPEN ACCESS This work is licensed under a Creative Commons Attribution-NonCommercial 4.0 International License. 
surgical techniques have been introduced to treat primary or secondary IOAA. These include myectomy, tenotomy, recession Z-myotomy, denervation-extirpation, and anteriorization $(I-3,6,7)$. The reported success and complication rates of these surgical procedures in the literature vary. The objective of this study was to assess the outcomes of recession and myectomy techniques performed in cases of primary IOOA.

\section{Methods}

The medical records of 94 patients who had been treated for primary IOOA in a single clinic between January 2012 and January 2017 were retrospectively analyzed. Informed consent was obtained from all of the patients or the parents of children before the operation. The principles of the Helsinki Declaration were observed at each stage of the study.

Patients with IOOA secondary to palsy of the superior oblique muscle were identified with the Parks-Bielschowsky three-step test and excluded from the study. In addition, patients with isolated +I IOOA unassociated with horizontal deviations, patients with vertical deviations, systemic disease, optic media opacity, retinal pathology, or previous strabismus surgery, were not included in the study.

After a detailed history of all of the patients was recorded, visual acuity tests, a cycloplegic refraction examination, and a detailed anterior and posterior segment evaluation were performed. Horizontal misalignment in the primary gaze position was measured using a prism cover test or the Krimsky test. Inferior oblique hyperfunction was classified as: $(0)$ absence of IOOA, $(+I)$ the pupil deviates slightly upward from the horizontal midline on adduction, $(+2)$ the upper edge of the pupil is tangential to the upper eyelid free edge during adduction, $(+3)$ the upper half of the pupil remains under the upper eyelid during adduction, and (+4) the whole pupil remains under upper eyelid during adduction.

Patients were classified into 2 groups according to the grade of inferior oblique hyperfunction. Recession surgery was performed in patients with +1 or +2 inferior oblique hyperfunction, and a myectomy was performed in patients with +3 or +4 inferior oblique hyperfunction. Patients with horizontal misalignment underwent horizontal muscle surgery with simultaneous inferior oblique surgery.

\section{Surgical Procedures}

General anesthesia was used in all of the study cases. Initially, the eyes of all of the patients were fixated to the superonasal position by placing a $4 / 0$ silk suture to the inferotemporal limbus.

Inferior oblique myectomy: In the lower temporal zone, the conjunctiva and Tenon's capsule were dissected 8 $\mathrm{mm}$ beyond the limbus border and the muscle was identi- fied and isolated with a muscle hook. The muscle was then detached from the sclera and an $8-10 \mathrm{~mm}$ section of the muscle was removed. The remaining muscle was released in the Tenon's capsule, and the conjunctiva was closed with 7-0 polyglactin sutures.

Inferior oblique $10-\mathrm{mm}$ recession: In the lower temporal zone, the conjunctiva and Tenon's capsule were dissected $8 \mathrm{~mm}$ beyond the limbus border and the muscle was identified and isolated with a muscle hook. The muscle was cut from the insertion region. Hemorrhage control was carefully performed by cauterizing the end of the released muscle. A 6-0 double-armed Vicryl suture (Ethicon, Inc., Somerville, NJ, USA) was passed through the muscle I $\mathrm{mm}$ behind the muscle end. The muscle was then reattached to the globe $2 \mathrm{~mm}$ laterally and $3 \mathrm{~mm}$ posterior to the insertion of the inferior rectus muscle. The conjunctiva was closed with 7-0 polyglactin sutures.

The absence of eye elevation in adduction at 6 months postoperatively was considered a successful outcome. All of the study patients were examined postoperatively on the first day, and at the first week, first month, and sixth month. Examinations were then performed every 6 months.

The statistical evaluations were performed with IBM SPSS Statistics for Windows, Version 22.0 (IBM Corp., Armonk, NY, USA). The Mann-Whitney $U$ test and the Fisher's exact test were used to analyze the data. A p value less than 0.05 was accepted as significant.

\section{Results}

The study included 134 eyes of 94 patients who had primary IOAA. The demographic features of the patients and the mean follow-up time in the surgical groups are shown in Table I. No significant difference was determined in the mean age, gender distribution, or length of follow-up between surgical groups. The strabismic characteristics of the patients in the surgical groups are presented in Table 2. There was no significant difference in the type of strabismus in the primary position, the presence of bilateral or unilateral IOOA, or the development of postoperative contralateral IOOA in patients with unilateral IOOA between the 2 surgical groups.

Table I. Demographic features of the patients and mean follow-up time in the surgical groups

\begin{tabular}{lccc} 
& Recession & Myectomy & P \\
\hline Mean age (years) & $7.20(2-37)$ & $7.14(2-33)$ & 0.93 \\
Gender (F/M) & $36 / 31$ & $12 / 15$ & 0.41 \\
Mean follow-up (months) & $15.17(6-47)$ & $19.81(6-68)$ & 0.74
\end{tabular}

F: Female; M: Male. 
Table 2. Strabismic characteristics of the surgical groups

\begin{tabular}{|c|c|c|c|}
\hline & Recession & Myectomy & $\mathbf{p}$ \\
\hline \multicolumn{4}{|l|}{ Primary position, n (\%) } \\
\hline ET & $48(71.64)$ & 17 (62.69) & \\
\hline $\mathrm{XT}$ & $13(19.40)$ & $6(22.22)$ & \\
\hline Ortho & $6(8.95)$ & $4(14.8 I)$ & 0.63 \\
\hline IOOA Bilateral & $34(50.75)$ & $12(44.45)$ & \\
\hline Unilateral & $33(49.25)$ & $15(55.55)$ & 0.95 \\
\hline IOOA in the fellow eye & $9(27.27)$ & $2(13.33)$ & 0.46 \\
\hline
\end{tabular}

ET: Esotropia; IOOA: Inferior oblique muscle overaction; Ortho: Orthotropia; $\mathrm{XT}$ : Exotropia.

Recession was performed in 95 (70.9\%) eyes and myectomy in 39 (29.1\%). The distribution of operated eyes according to the severity of IOOA is shown in Figure I. Surgical success was achieved in 38 of 39 (97.4\%) eyes that underwent myectomy and 92 (96.8\%) of 95 eyes that underwent recession. Horizontal muscle surgery was performed simultaneously with inferior oblique surgery in 84 (89.3\%) patients who had horizontal strabismus. Specifically, 65 (69.1\%) were esotropic patients and 19 (20.2\%) were exotropic. After surgery, II (22.9\%) of 48 patients with unilateral IOOA subsequently developed a contralateral overactive inferior oblique muscle.

IOAA persisted in 3 eyes $(3.1 \%)$ in the recession group and in I eye $(2.5 \%)$ in the myectomy group at the postoperative sixth month. A conjunctival epithelial cyst was observed in I patient who had recession surgery. No other potential surgical complications, such as hypotropia in the primary position, scleral perforation, or fat adherence syndrome, were observed.

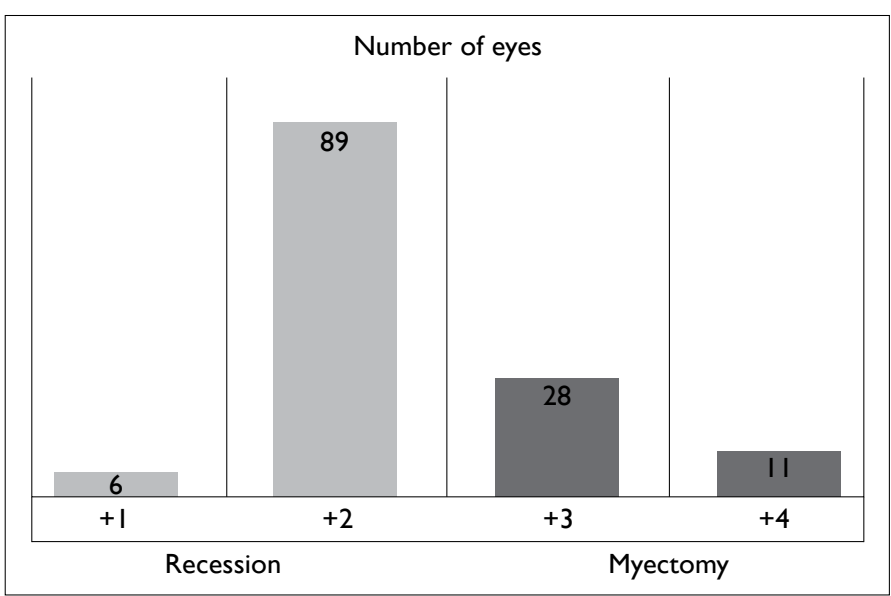

Figure I. Distribution of surgically treated eyes according to the grade of inferior oblique muscle overaction.

\section{Discussion}

Several surgical methods have been defined to treat IOOA and the decision regarding surgical method is based on the preference and experience of the surgeon, as well as the severity of the IOOA $(1,8,9)$.

Recession of the inferior oblique muscle, I of the 2 most commonly performed procedures, can be performed in patients with low-grade IOOA $(9,10)$. In this procedure, the insertion of the muscle is fixed lateral and posterior to the insertion site of the inferior rectus muscle and recession can be adjusted according to the degree of hyperfunction, a 6-mm recession is generally performed for +1 overaction, $10-\mathrm{mm}$ for +2 overaction, and $14-\mathrm{mm}$ for +3 overaction ( 1 , II). The recession procedure is more difficult than myectomy and requires a longer operation time (9).

In a study conducted by Rajavi et al. (12), 82 eyes with IOOA were randomly selected for either recession or myectomy surgery, and recession was demonstrated to be effective at eliminating overactive inferior oblique muscle. In the recession group, the inferior oblique muscle was sutured to the globe at a point $4 \mathrm{~mm}$ posterior and $2 \mathrm{~mm}$ temporal to the inferior rectus muscle insertion in 40 eyes. Shipman and Burke (10) also reported that recession was successful in reducing IOOA in a study of 24 patients with +2 or more inferior oblique hyperfunction who were randomly assigned to either recession or myectomy surgery. In their study, a $10-\mathrm{mm}$ recession was performed to treat inferior oblique hyperfunction in II patients. Furthermore, Alajbegovic-Halimic et al. (I) recessed the inferior oblique muscle in 23 patients who had primary IOOA and reported that recession was a safe and effective means of eliminating inferior oblique hyperfunction.

In our study, the inferior oblique muscle was recessed to a location $2 \mathrm{~mm}$ lateral and $3 \mathrm{~mm}$ posterior to the insertion of the inferior rectus muscle in patients with +1 or +2 IOOA and a surgical success was achieved in 92 of 95 eyes $(96.8 \%)$ when a successful outcome is defined as no affected eye elevation in adduction at 6 months postoperatively. In 3 eyes (3.1\%), inferior oblique hyperfunction persisted. One patient had +2 IOOA and 2 had +I IOOA. Parks (I3) reported residual inferior oblique hyperfunction of $19 \%$ in cases who underwent recession of the inferior oblique in both eyes. Our results of the frequency of residual overaction were lower. Though we recessed the inferior oblique muscle to the location as Parks did, the difference may be due to the degree of inferior oblique hyperfunction in our recession group. We used the recession technique only in cases with +I or +2 inferior oblique hyperfunction, whereas Parks applied the method in cases with any degree of inferior oblique hyperfunction. In the same study, Parks reported postoper- 
ative residual IOOA in $10 \%$ of patients with slight inferior oblique hyperfunction. We performed a $10-\mathrm{mm}$ recession of the inferior oblique muscle in patients ( 6 eyes) with +1 inferior oblique hyperfunction to avoid residual IOOA. Postoperatively, none of these mild cases demonstrated inferior oblique dysfunction. The patient with residual +2 IOOA in our study required additional surgery.

Myectomy, another commonly performed procedure, is mainly used in the treatment of patients with +3 IOOA. In the inferior oblique myectomy technique, the muscle is cut at the insertion and a segment of the muscle is excised, after which the remaining part of muscle is released in the Tenon's capsule. The procedure is simple and requires only a short operation time $(10,14)$.

Rajavi et al. (12) performed recession on 40 eyes and myectomy on 42 eyes to treat inferior oblique hyperfunction and they reported that both techniques were effective in reducing IOOA. In their study, recession or myectomy was applied randomly to eyes with inferior oblique hyperfunction, with a 5-mm section of the inferior oblique muscle excised in the myectomy group. Sanjari et al. (2) performed a myectomy in 91 eyes, anterior transposition in 19 , and disinsertion in 12 for the treatment of IOAA, and obtained a success rate of $97.8 \%$ with the myectomy technique, $89.5 \%$ with anterior transposition, and $91.7 \%$ with disinsertion when IOOA $<+1$ is considered a satisfactory outcome. In their study, the type of surgical procedure used was dependent on the preference of the surgeons, and a 5-mm or larger resection of the inferior oblique muscle was used in each eye in the myectomy technique (2). In a study of 24 patients with +2 or more inferior oblique hyperfunction in which either myectomy or recession surgery was performed, Shipman and Burke (10) reported that the myectomy procedure was effective for reducing IOOA. In that study, the inferior oblique muscle was cut at the lateral edge of the inferior rectus in 12 patients who underwent myectomy surgery.

In the current study, an 8-10-mm portion of the inferior oblique muscle was removed in cases with +3 or +4 inferior oblique hyperfunction and surgical success was obtained in 38 of 39 eyes $(97.4 \%)$ when no overelevation of the affected eye during adduction at the postoperative sixth month is considered a successful outcome. In our myectomy group, a few patients had an inferior oblique underaction in the early postoperative period, but this dysfunction improved in all patients in the first 6 months of the postoperative period. In I eye (2.5\%), a residual + I IOOA was diagnosed. In some early studies, the rate of residual IOOA after myectomy surgery ranges between $1.8 \%$ and $5.4 \%(2,3,15)$. Our rate of postoperative residual inferior oblique hyperfunction was within this range.

Our study is limited by the retrospective design. In ad- dition, the study did not have control groups to perform comparisons, and there are no data related to pattern strabismus, especially V-pattern strabismus, which is related to overaction of the inferior oblique muscles. Finally, the minimum follow-up in the postoperative period was relatively short (6 months); a longer postoperative follow-up time is needed to assess the long-term effects of both recession and myectomy surgery.

\section{Conclusion}

In conclusion, the results of current study indicated that both recession and myectomy procedures are effective options for surgical treatment of primary inferior oblique hyperfunction when they are used according to the degree of inferior oblique hyperfunction. We think that classifying patients with primary IOOA based on the required surgical method simplified the surgical treatment of these patients. Further studies with a large sample size and a longer followup period will be needed to validate our results.

This manuscript was presented at the $5 \mathrm{I}^{\text {st }}$ National Congress of the Turkish Ophthalmological Association in Antalya, Turkey, 2429 October, 2017.

\section{Disclosures}

Ethics Committee Approval: Retrospective study.

Peer-review: Externally peer-reviewed.

Conflict of Interest: None declared.

Authorship Contributions: Involved in design and conduct of the study (EO, AG, EO); preparation and review of the study (AG, EO, $\mathrm{CC})$; data collection (AG, EO); and statistical analysis (EO, CC).

\section{References}

I. Alajbegovic-Halimic J, Zvizdic D, Sahbegovic-Holcner A, Kulanic-Kuduzovic A. Recession Vs Myotomy-Comparative Analysis of Two Surgical Procedures of Weakening Inferior Oblique Muscle Overaction. Med Arch 2015;69:165-8. [CrossRef]

2. Sanjari MS, Shahraki K, Nekoozadeh S, Tabatabaee SM, Shahraki $\mathrm{K}$, Aghdam KA. Surgical treatments in inferior oblique muscle overaction. J Ophthalmic Vis Res 2014;9:29I-5.

3. Chang BL, Yang SW. Inferior oblique overaction. Korean J Ophthalmol 1988;2:77-8I. [CrossRef]

4. Wilson ME, Parks MM. Primary inferior oblique overaction in congenital esotropia, accommodative esotropia, and intermittent exotropia. Ophthalmology 1989;96:950-5. [CrossRef]

5. Moon K, Lee SY. The effect of graded recession and anteriorization on unilateral superior oblique palsy. Korean J Ophthalmol 2006;20:188-91. [CrossRef]

6. Mostafa AM, Kassem RR. Comparative study of unilateral versus bilateral inferior oblique recession/anteriorization in unilateral infe- 
rior oblique overaction. Eur J Ophthalmol 20I8;28:272-8. [CrossRef]

7. Del Monte MA, Parks MM. Denervation and extirpation of the inferior oblique. An improved weakening procedure for marked overaction. Ophthalmology 1983;901 I78-85.

8. Goncu T, Cakmak S, Akal A, Oguz H. The effect of anterior transposition of the inferior oblique muscle on eyelid configuration and function. Indian J Ophthalmol 2016;64:33-7. [CrossRef]

9. Lee DC, Lee SY. Effect of modified graded recession and anteriorization on unilateral superior oblique palsy: a retrospective study. BMC Ophthalmol 20I7;17:27. [CrossRef]

10. Shipman T, Burke J. Unilateral inferior oblique muscle myectomy and recession in the treatment of inferior oblique muscle overaction: a longitudinal study. Eye (Lond) 2003; 17:1013-8.

I I. Mims JL 3rd, Wood RC. Bilateral anterior transposition of the inferior obliques. Arch Ophthalmol 1989;107:4I-4. [CrossRef]

12. Rajavi Z, Molazadeh A, Ramezani A, Yaseri M. A randomized clinical trial comparing myectomy and recession in the management of inferior oblique muscle overaction. J Pediatr Ophthalmol Strabismus 201 I;48:375-80. [CrossRef]

13. Parks MM. A study of the weakening surgical procedures for eliminating overaction of the inferior oblique. Trans Am Ophthalmol Soc 1971;69:163-87.

14. Min BM, Park JH, Kim SY, Lee SB. Comparison of inferior oblique muscle weakening by anterior transposition or myectomy: a prospective study of 20 cases. Br J Ophthalmol 1999;83:206-8.

15. Davis G, McNeer KW, Spencer RF. Myectomy of the inferior oblique muscle. Arch Ophthalmol 1986;104:855-8. [CrossRef] 